\title{
بنية الشخصية في روايات طارق الطيب بحث مستل من رسائت الماجستير بعنوان: \\ البنية السردية في روايات طارق الطيب دراسة سردية دودية
}

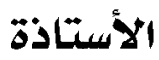

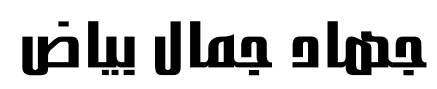 \\ باحثت ماجستير - قسهر الدراسات الأدبيت

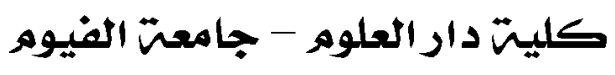

\section{إشراف}

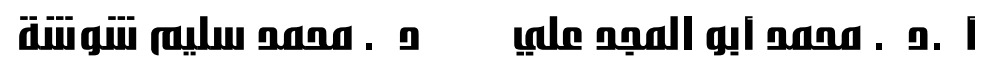

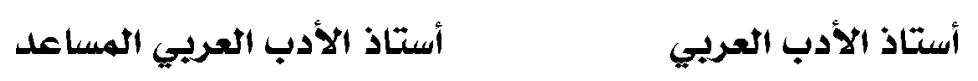

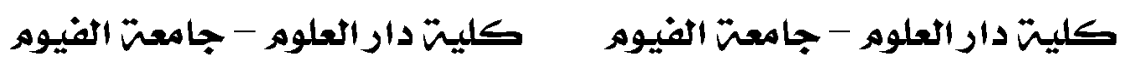

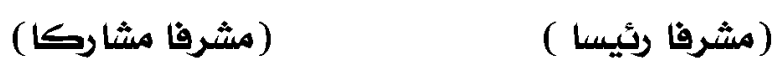


بنية الشخصية في روايات طارق الطيب 


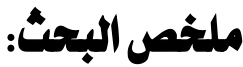

الشخصية الروائية هي عنصر مهم من عناصر البناء الروائسي، تتشــكل

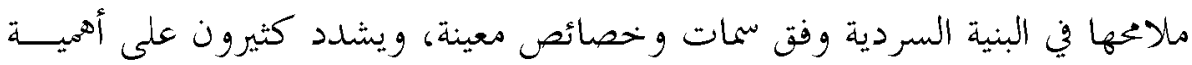

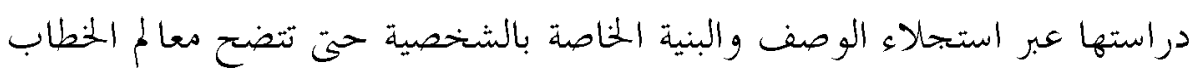

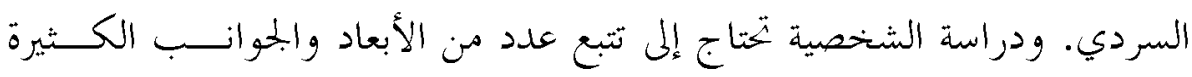

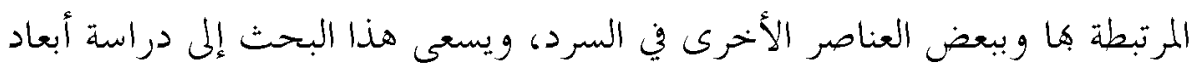
الشخصية الروائية في النتاج الإبداعي لطارق الطيب.

\section{الكلمات الاقتتاحية :}

الشخصية ، أهمية دراسة الشخصية ، الثخصية في روايات طارق الطيب

\section{Research Summary:}

The novelist character is an important component of the novelistic construction, its features are formed in the narrative structure according to certain features and characteristics, and many stress the importance of studying it by clarifying the description and structure of the character until the features of the narrative discourse become clear. And the study of the personality needs to follow a number of dimensions and the many aspects associated with it and some other elements in the narration, and this research seeks to study the dimensions of the novelistic personality in the creative output of Tariq Al-Tayeb.

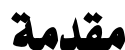

الشخصية الروائية هي عنصر مهم من عناصر البناء الروائي، تتشكل ملاعها في البنية السردية وفق سمات وخصائص معينة، ويشدد كثيرون على أهمية دراستها عبر استجلاء الوصف والبنية المناصة بالشخصية حتى تتضح معالم الخطاب

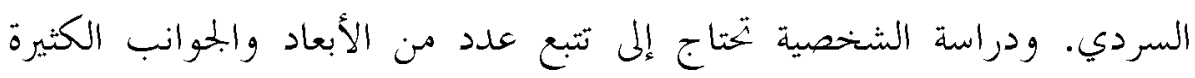

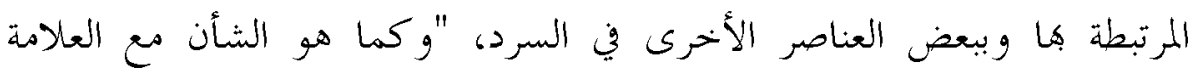

مجلت كليت دار العلوم جامعت الفيوه العدد ه م إصدار يونيو .r.r 
اللسانية فإن الشخصية لا تتحدد من خلال موقتها داخل العمل السردي (فعنها) فقط، ولكن من خلال العلاقات التي تنسجها مع الشخصيات الأخرى أيضا، إذا تدخل في عمليات تبادل اجتماعي، ضمن مرجعية النص، مع وحدات من مستوى أعلى (العوامل) أو وحدات أدنى (الصفات المميزة التي تحدد فردا قابلا لأن يصبح

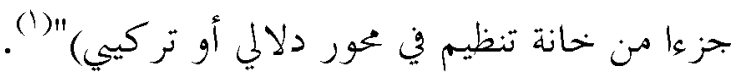
وفي الغالب تكون الشخصية هي مخور السرد، ويقوم السرد بالإخبار عنها، ويتحدث فيها أي يعبر عن صوها، ويدور حولها، "تبدأ الحكايات عامة بالأخبار عن خروج شخصية من شخصياةا، هي عادة الشخصية الرئيسة(البطل أو البطلة)، ويكون الخروج خروجا من البيت أو خروجا عن الطاعة، أو تحركا نهو غاية.. تشكل هذه البداية الحلقة الأولى من حلقات السياق السردي، وتتعرض الشخصية الرئيسة البطل أو البطلة إلى صعوبات تعوق سيرها وبالتالي وصولها"(؟). وخروج البطل المهاجر من وطنه نيو تهقيق ذاته في أغلب روايات طارق الطيب يمثل حدثا مركزيا نابعا من الشخصية وطموحها لحياة أفضل، هو جوهر ورئه وريزة الفعل الروائي ومصدر الأحداث الأخرى، ولكن الفارق أنه لا يكون في الترتيب السردي تهري

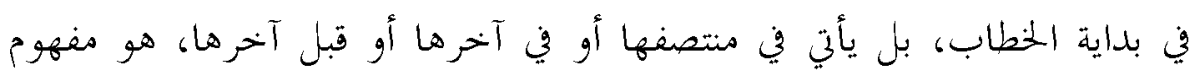
بداهة وبشكل طبيعي، ومتحقق من فكرة الهجرة ومن طبيعة المكان ومن هوية

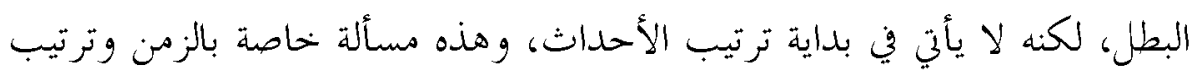
الأحداث وفت نظام معين اختاره الكاتب. و لم تعد الفكرة في الشخصية الروائية مخور العمل، بمعنى أن كل العناصر الأخرى تكون هامشية، وإنا هي جزء من كل، ووحدة بين العناصر الأخرى، وأحيانا ما تتراجع في بعض الأعمال وظائف الشخصية فيهيمن المكان أو الزمن، ولكن لا يعين هذا غياها أبدا. ويكون الهدف من رسم ملامح الشخصية أها تكون جزءا من بنية كاملة، لا فرض الشخصية بمعزل أو انفصال عن بقية العمل. "إن ريم 
غاية الكتاب الجحدد في تعاملهم مع الشخصية أفم يثبتون للقارئ لا تاريخية هذه الشخصية، ولا و اقعيتها، بل وجوديتها، ولكن على أها كائن من ورق مثلها مثل اللغة والحدث والزمان والحيز والمشكات السردية الأخرى؛ حذو النعل بالنعل" (ب).

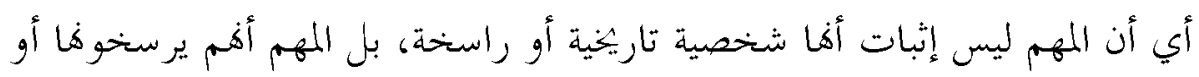

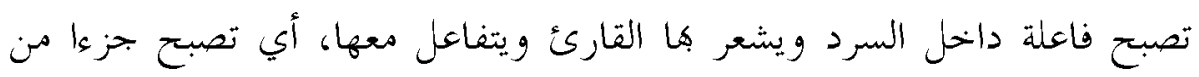
حقيقة البناء السردي، ويكفي أن تكون مصدقة ومقنعة داخل السرد. وتكتسب الشخصية الروائية قيمتها من علاقاها مع الشخصيات الأخرى

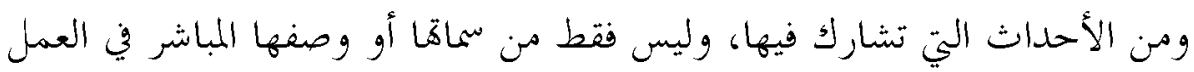
الروائي، "ومدلول الشخصية أو قيمتها (إذا أخذنا بمفاهيم سوسير) لا يتشكل فتط

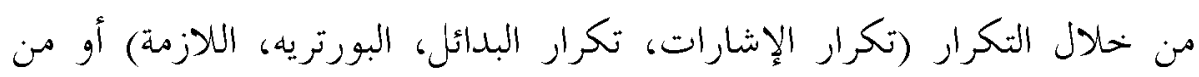
خلال التراكم والتحولات (من أقل تحديد إلى أكبر تحديد)، ولكن يتشكل أيضا

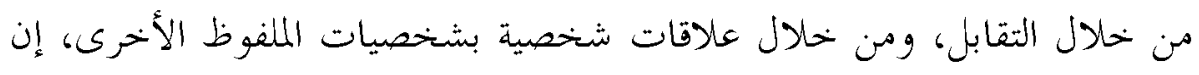
هذه العلاقة - يبجب أن نؤ كد ذلك - تتغير من مقطع إلى آخر، إذا تتحرك على تحنى مستوى الدال كما تتحرك على مستوى المدلول (شخصية تمارس الجنس مقابل أخرى مخرومة منه)، وذلك وفت روابط من التشابه والاختلاف" (؟). ولهذا سنحاول في هذه الدراسة النتقيب في سمات عدد من الشخصيات لاستكشاف ملامعها وديا ووظيفتها وقيمتها وما ينتج عنها في البنية السردية. وعملية تحليل الشخصية تتطلب عددا من الإجراءات، ومثلما تحتاج لربطها

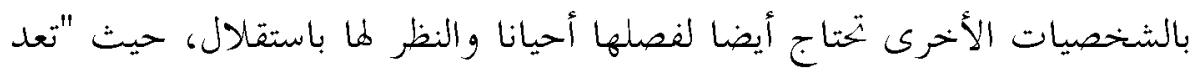
الشخصية وحدة دلالية، وذلك في حدود كوفا مدلو لا منفصلا. وسنفترض أن هذا المدلول قابل للتحليل والوصف. وإذا قبلنا فرضية المنطلق القائلة بأن الشخصية في

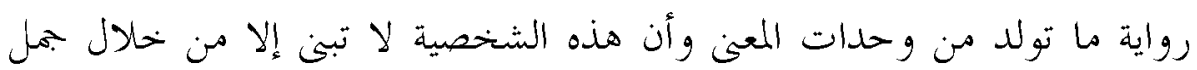

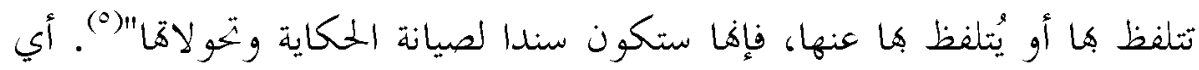


أن هذا الفصل لعنصر من عناصر البناء الروائي هو فصل مؤقت لهدف التحليل، وهو لا يعني اجتزاء له من بقية العناصر الأخرى، فهو أقرب لوضعية تحليلية فقطر. أي البحث عن قيمتها ومعناها ودورها الوظيفي في ذاتها.

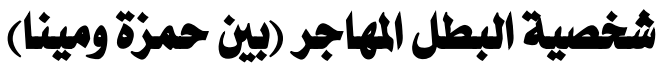

يغلب على نموذج البطل في روايات طارق الطيب المعاناة وسمات الانقسام

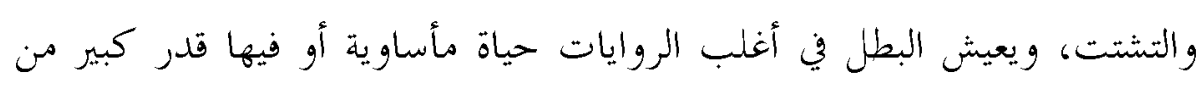

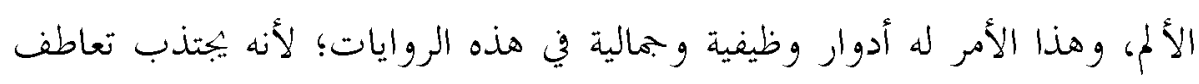
المتلقي، ويشعره بالاخياز مع هذا النموذج أو تلك الشخصيات المأساوية. وله وله

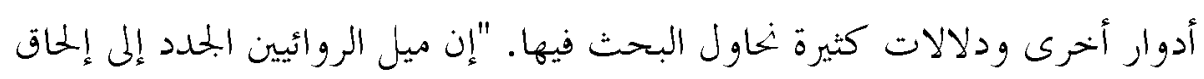

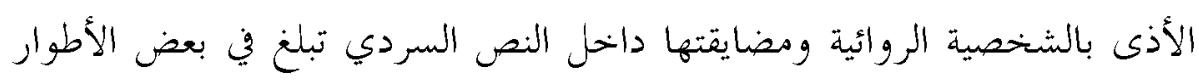
حد الاضطهاد، ثم ميلهم إلى التزعة الأسطورية في تفسير بعض القيم أو تحليلها،

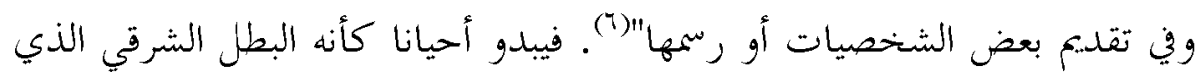
يتصور أنه سيغزو الغرب والحضلارة الغربية بعلمه وطموحه وقدراته الخاصة، ثئم يفاجأ بأنه شخص ضعيف وعاجز ومنتهك أو مسلوب الإزادة و كأن الدنيا كلها

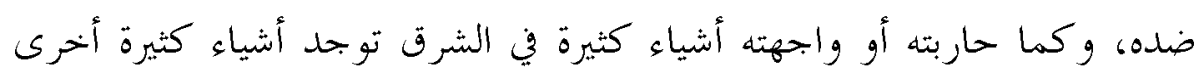
تواجهه وتجايهه في الغرب أيضا وقد يكون بشراسة أشد من السابق.

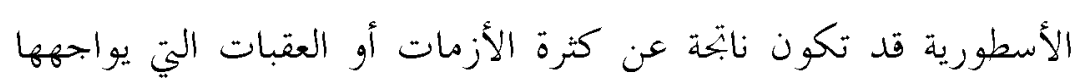
البطل في حياته، فهي ليست أسطورية مععن الخرافة أو غير المنطقية أو غير المقبولة،

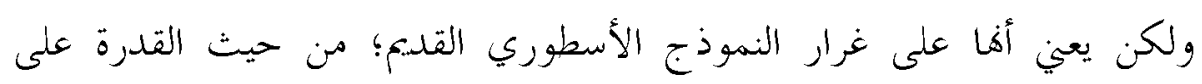

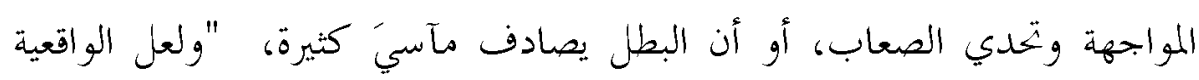

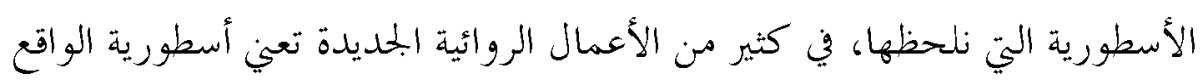
المعيش، كما تعني السخط على هذا الوجود ذاته. وهذه الأسطورية التي نتحدث عنها ليست صوفية، نرفض الحياة الدنيا وتزهد فيها زهدا، وترغب عنها رغبا، وإنما 
هي أسطورية ترفض الصوفية وتحب الحياة وقواها، ولكنها مع ذلك تقلق فيها

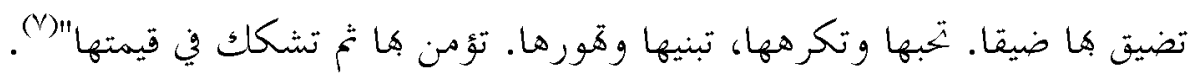
ولا يعين أسطورية البطل أنه خارق أو قوي على الدوام، وإنما هو مزيج من القوة والضعف، من القدرة والعجز. يشعر البطل بكالة من الانتهاك الجسدي في رواية وأطوف عاريا ويبدو هناك تركيز على الجسد وأبعاده، ويصبح الجسد جزءا من أزمة هذا البطل أو إشكاليته؛ حيث يشعر بأنه مباح وهناك اعتداء على خصو صيته وحقوقه الفردية، وهكذا يظهر مقدار قسوة المختمع الأوربي الحديث الذي لجأ إليه وسافر ليحتمي به مانه من قسوة المختمع الشرقي، فكأنه مثل المستجير من الرمضاء بالنار كما يقول المثل

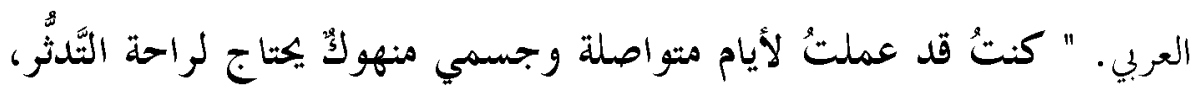
فراحته تأتي من حَجْب عُرْيه؛ عندما تقف عيون الناس عند حدود الملابس ولا تتجاوزها إلى أبعد من ذلك. كنت أشعر بتلاشي الإجهاد بمجرد ارتداء ملابسي. أحسستُ برؤوحي تحلّق وأنا جالس في كافتيريا المعهد أثرب قهوبي في

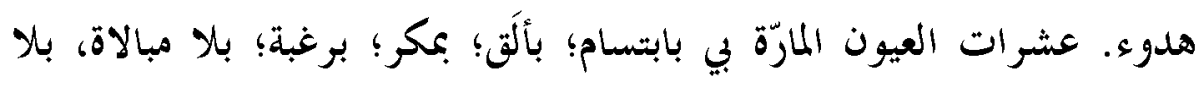

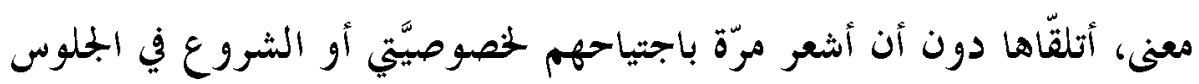

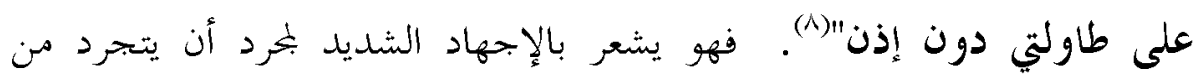
ملابسه ويعرض جسده على الطلاب في أكادمية الفنون، ويتلاشى الإجهاد تماما كمجرد ارتداء الملابس.

وهذا الانتهاك للبطل ليس انتهاكا لذاته المفردة وركنه يمكن أن يكون دالا على انتهاك ثقافته وقيم بمتمعه كله، ولذلك نراه ينتقل من تعريه هو في فيينا إلى انتهاك الإنسان العربي في العراق في أحداث التعذيب والتعرية التي مارسها المنود الأمريكان على المواطنين العراقيين. تأتي مشاهد الانتهاك من خلالِل التلفزيون ولكنها تصبح متوازية مع حالثه الراهنة ويقارن كيف أن الثقافة الأخرى التي 
ينظمون الأعمال الخيرية للحفاظ على حقوق الحيوانات ينتهكون حقوق البشر في السجون أو في بحتمعاهم. " هل كان علاجحُا أن أكون هناكَ أو أن أتأمَّل ما لم

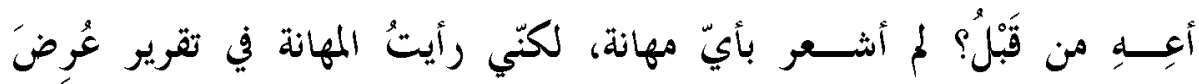
بالصدفة مساء اليوم نفسه على قناة ألمانية عن سجن (أبو غريب) في العراق.

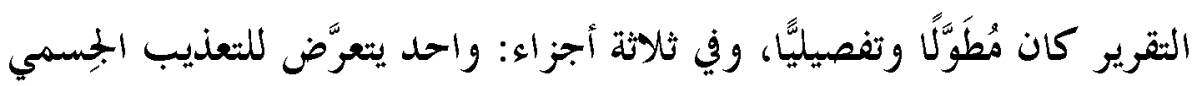
عبر التاريخ، وواحد لِمًا حدث في سجن (أبو غريب) مع الضحايا بصوتم مع ترجمة مكتوبة على الثاشة، وواحد في أمير كا مع الجنود الأمريكان المُصابين بأمر اض نفسية نتيجة الحرب البشعة، أو نتيجة تجاوزاتمم"(9). هو لم يشعر بالمهانة

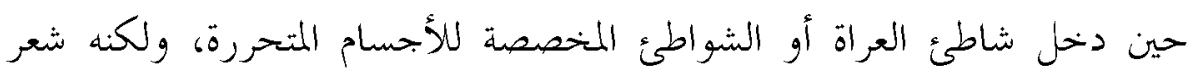

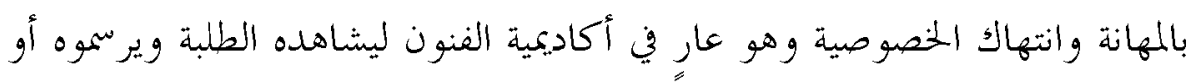
يدرسوا جسده، والنحظة الثانية التي شعر فيها بالإحساس نفسه من المهانة والانتهاك حين شاهد الانتهاكات الشنيعة التي حدثت في سجن (أبو غريب) في العراق. يبدو أن الكاتب حين وضع المشهدين أو الحالتين بجوار بعضهما أراد أن يطابق بين مهانة مينا بطل الرواية وانتهاكات السجون، ليشعر بنفسه فيهم أو يرى

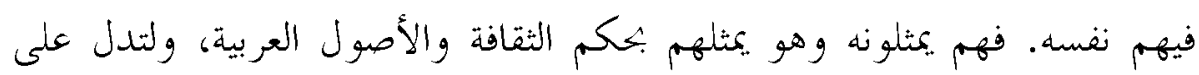
تفوق الإنسان الغربي وأزمة الإنسان العربي واهزامه أمامه.

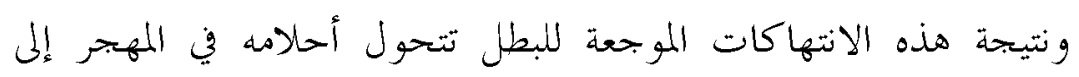

كوابيس، لا يرى فيها غير الوحوش التي تنهش جسده. "رُحتُ في غيبوبة تُشبه

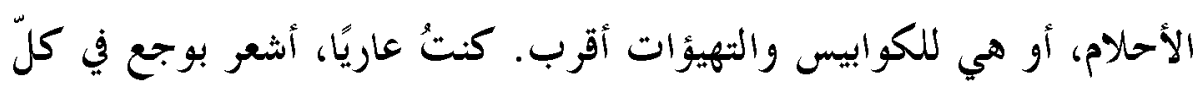
خلية في جسمي، وأسـمع صليل سلاسل وأقفال. نباح فظيع لكلاب مسعورة

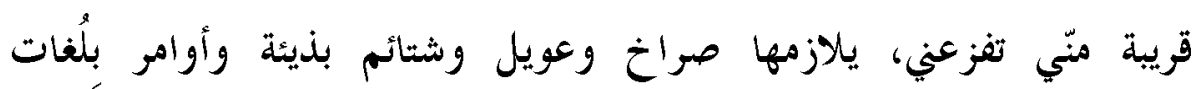

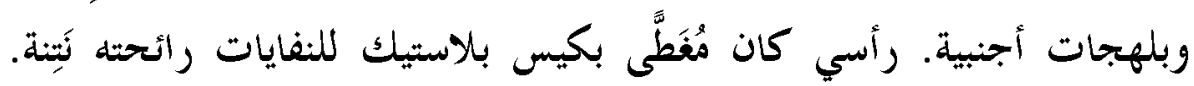

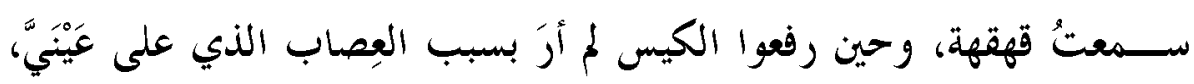




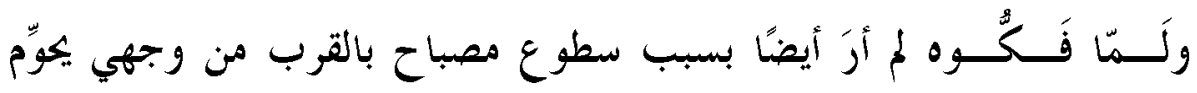

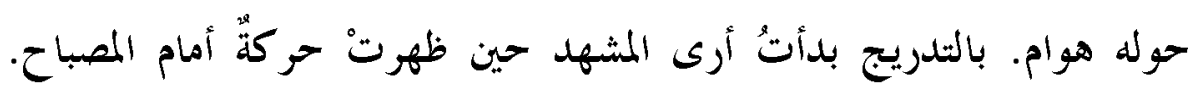

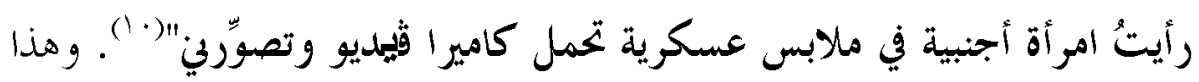
الحلم بذاته يدل على أنه يرى نفسه في هؤلاء المساجين من نزلاء سجن (أبو

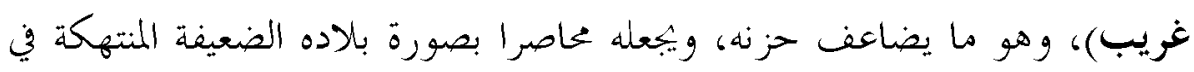
مكاها، وهو المنتهك في غربته، فلا فرق بين الذين فروا إلى الغرب والذين ظلوا في

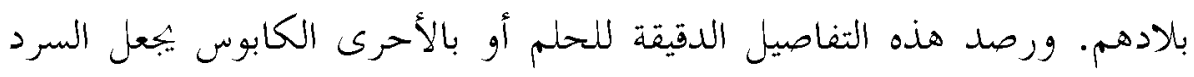
أكثر ألما ويظهر عمق مشاعر الشخصية وهو إجسها أو مخاوفها. في غالبية روايات طارق الطيب يأتي السرد بضمير المتكلم وبصوت البطل الشخصية الرئيسة في الرواية، والبطل يعلن دائما موقفه من الحياة ومن العالم ويكشف بنفسه عن سماته وعن موقفه النفسي ويصرح بمشاعره بشكل دائم، كما

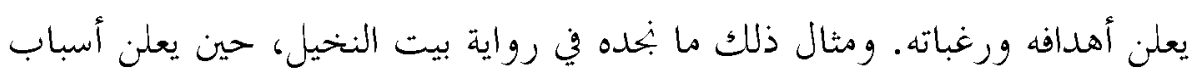

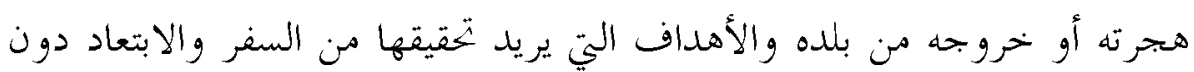
أن يمدد مكانا يذهب إليه:

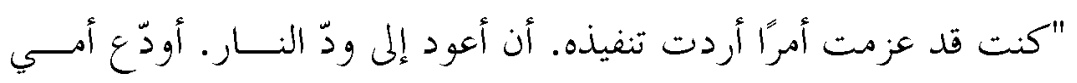
وحليمة وكريمة للمرّة الأخيرة وأن أبحث عن طريقة لمغادرة هذه البلاد. لم يعد هنا

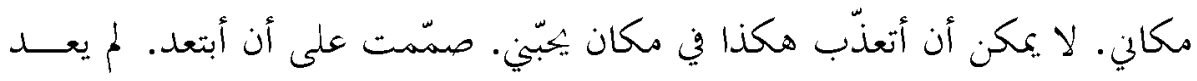
لي أهل هنا ولا أقارب. وليس هناك من سيبكي على رحيلي ولا من سيفتقدني. أنا

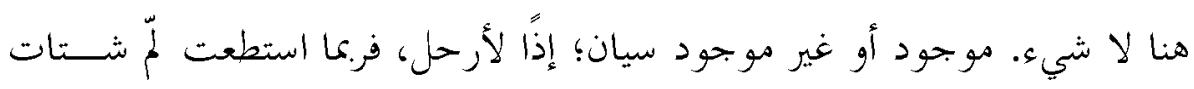

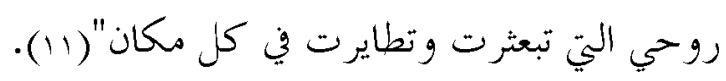

ومن الأدوات التي أسهمت في تشكيل شخصية حمزة في رواية بيت النخيل تقنية الحلم؛ لأكا كشفت عن الجانب الخفي في شخصيته أو المطمور، والمساحة المرتبطة باللاوعي، " فيبقى الحلم بوصفه حدثا روائيا نوعا من مقاومة حال الموات 
أو المرض التي يعانيها حمزة في مهجره، بغض النظر عما إذا كانت هذه الخحاولة

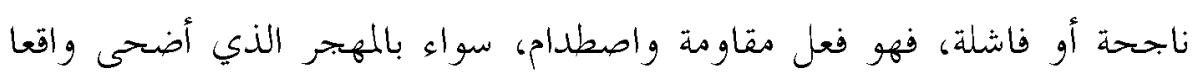

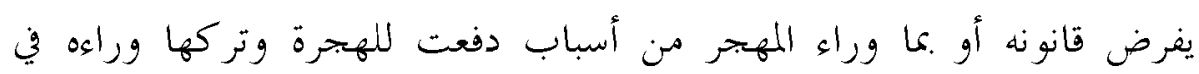

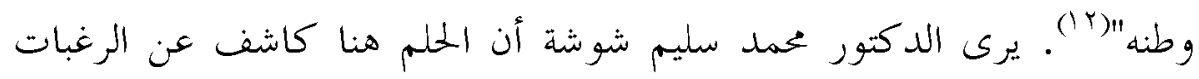

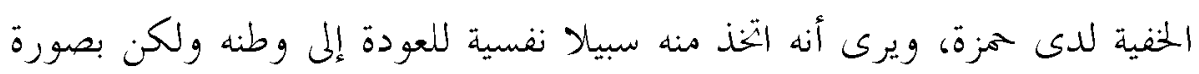

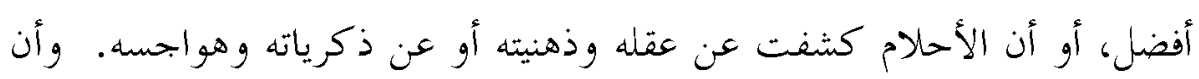

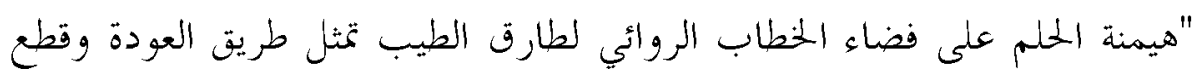
الغربة، وسبيلا من سبل العودة إلى الوطن برغم آلامه ومساوئه، ليتأكد حال

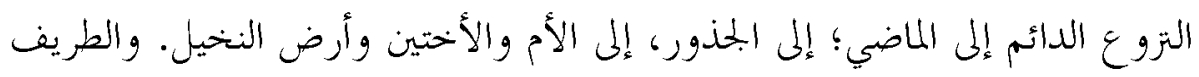

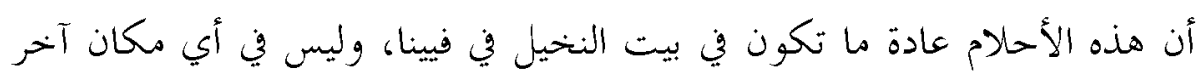

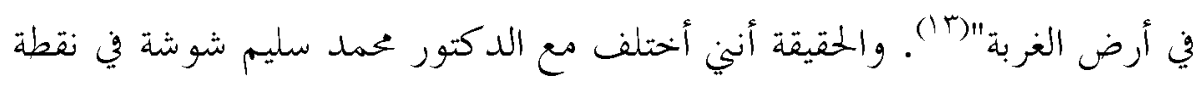
واحدة، وهي أن هذه الاستعادة للوطن عبر الحلم لا تمثل رجوعا إليه بل هي تهري

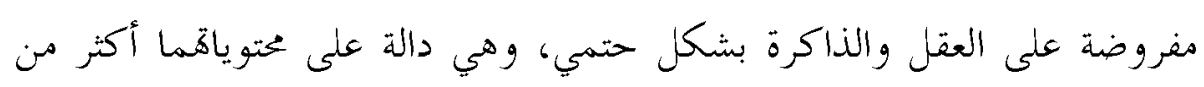
دلالتها على الرغبة في العودة؛ لأن بعض أحلام العودة كابوسية ويغلب وعلى عليها

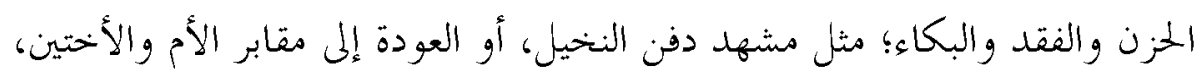

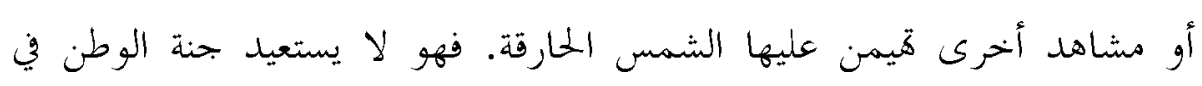
أحلامه، بل أحيانا ما تطارده كو ابيسه.

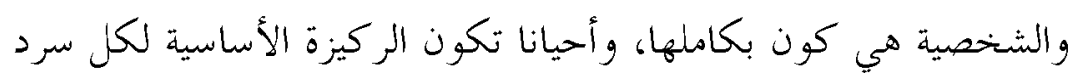
روائي؛ فمنها تنبع الأفعال والأحداث، والسرد في الأساس يقوم على الإنسان، ولى ولى

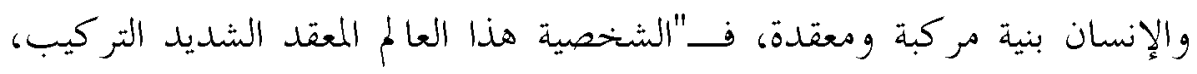
المتباين المتنوع.. تتعدد الشخصية الروائية بتعدد الأهواء والمذاهب والأيديولوجيات و الثقافات والحضارات والمواجس والطبائع البشرية التي ليس لتنوعها ولا لاختلافها

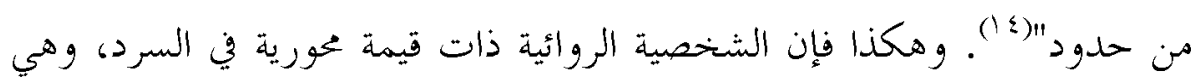


بطبيعتها مركبة من طبقات عديدة لكون الإنسان دائما ما تتداخل في تكوينه عناصر كثيرة. وفهم الإنسان أو الشخصية يسهم كثيرا في فهم السرد والمعرفة

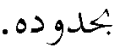

"فشخصية (مينا سليمان محمود عبد الماجد) الشاب المصري المهاجر إلى فيينا هي نموذج خاص بطارق الطيب الذي ينحت تمثاله الخاص بقدر عال من الفنية

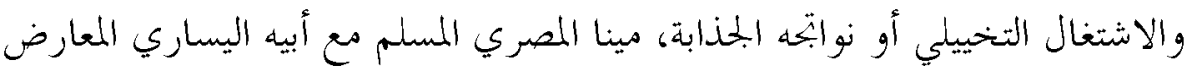
في مدة الستينيات والسبعينيات وغيرها من الشخصيات نماذج ثرية تم تشكيلها أو بناؤها وفق تركيبة إنسانية تتجاوز السطحية تماما وتبتعد عن التنميط المعهود أحيانا في كثير من الروايات، فالشخصية تتشكل وفق منطق بنائي يهتم أو ينشغل من البداية بالسمات النفسية أو البنية العميقة للشخصية، فلدينا بناء للذاكرة أو بناء لوعي الشخصية ولاوعيها وتثافتها، ولدينا كذلك ما بمكن أن يسمى ببناء مصادر الألم الخاصة، فكل شخصية لها ألمها الخناص أو منابعه الخاصة التي تصبح هذه المنابع دليلا أو علامات على هذه النماذج الإنسانية وبتعلها مميزة ومختلفة، فالرسم السردي يعمل ابتداء من داخل هذه الشخصيات ويأتي عبر نسج هادئ للتغاصيل والحكايات والذكريات القديمة والجديدة وامتزاجها كلها داخل الذاكرة وداخل وعي الشخصية ومعارفها التاريخية"(0). ولمذا فإن المعاناة التي يلاقيها البطل المهاجر في روايات طارق الطيب تكاد لا تنتهي، أو مستمرة على مدار حياته في الغربة، مثلما كانت في الوطن أيضا. فهو إذا كان في وطنه يعاني من الفقر والتسلط وعنف الأب أو شيخ الكُّاب، فإنه يعاني أيضا في المهجر من أشياء عديدة، بعضها يكون هزليا أو عبثيا ويتحقق في تفاصيل صغيرة؛ مثل اضطهاد الآخر له، أو معاناته من البرد أو الفقر أو التجول في وسائل المواصلات. وحين يعثر على حبيبته ساندرا فإنه يعاني بفقدها وموها، حين أصيبت بالسرطان وماتت صغيرة وتر كته في وحدته المتجددة. وبين المشاهد الصغيرة؛ مثل 
أن عدم اعتياده على البرد والمطر يبعل مشترياته تتبعثر على السلم ويجمعها وهو مشحون بالغضب والخوف. ويبدو هذا المشهد اختزالا بسيطا لما يعانيه البطل في حياته في المهجر: " الآن تنشرخ من قعرها فجأة. صوت ثنزّق سريع يتبعه انيار. يتلدرج رغيف الحبز إلى أسفل السلّم ويسقط البيض على السكر والثاي

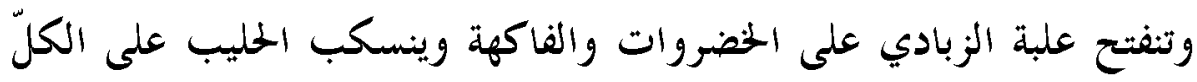
وتكاد زجاجة الزيت تنكسر، أحاول بتلقائية أن أحيها بقدمي، فتسقط بقوة على قدمي اليسرى وتؤلمني، لكنها لا تنكسر. زجاجة الخلّ تنفَلقِ وتصعد رائحتها نفاذة. للحظة تبدو الثنطة في حضني الآن عبثية المنظر وفي منتهى الحفّة، فارغة ومشروخة القعر، وأنا في وجه مغتاظ ألعن المطر السخيف والسلّم

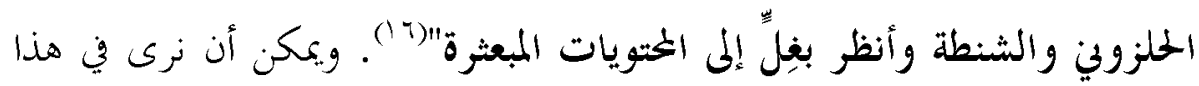
المشهد جانبا رمزيا؛ حيث إنه يتحمل دلالات حول فكرة الخيبة، وأن الكيس الذي لئي تمزق وسقطت محتوياته هو أقرب لأن يكون حصيلة العمر أو ما لديه من ذكريات

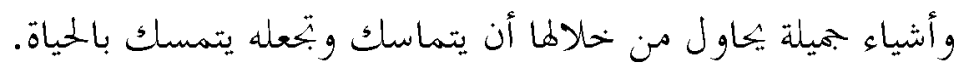
ومصادر معاناة البطل في روايات طارق الطيب كثيرة؛ بعضها يكون من المهجر، و بعضها يكون بسبب الوطن أو الأصول والعرق، حتى إن معاملته في بلاد الغرب تكون بمثل معاملته في قوانين الوطن من المنع والتحريم، و كأن قوانين بلاده مازالت تطارده في المهجر، ولا تتم معاملته في الغرب بقوانين الغرب من حريات، ويظهر هذا في المشهد الذي يضطر فيه لأن تخبئ حبيبته كاتارينا رأسه في حجرها وهما يبجلسان في حديقة عامة وسط محبين آخرين غيرهما، ولكنه هو فقط الذي يضطر لمذا الإخفاء حتى لا تتم معاقبته. يقول مينا بطل الرواية عن هذا المشهد:

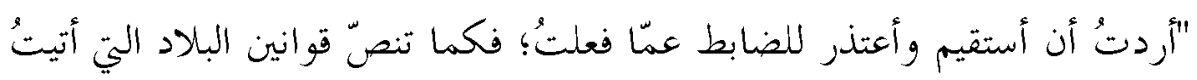

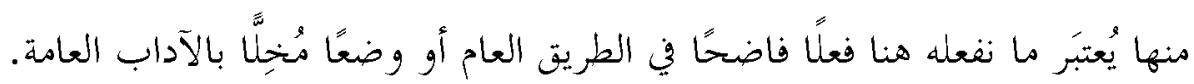

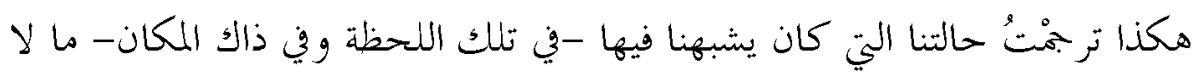


يقلُّ عن عشرة محبِّن ومُحِبّات، ولكنين لستُ من هنا؛ وعليه فقو انين بلادي ستنال

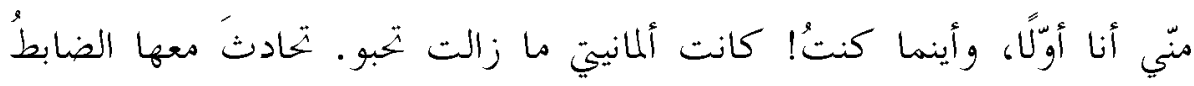

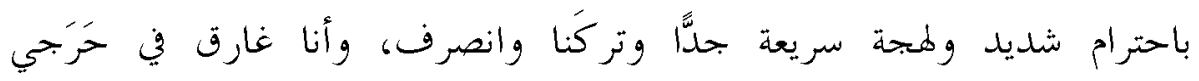

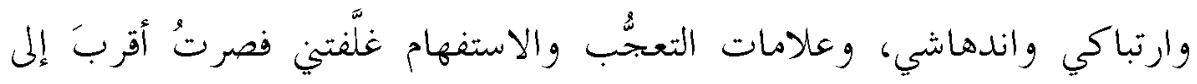

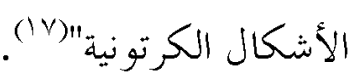

هنا تعامل معها الضابط باحترام وتقدير، لكنه لم يتعامل معه هو، وهو

اضطر للتخفي أو لإخفاء اقترابه منها. يقول البطل إن قوانين بلادي ستنال مين أنا

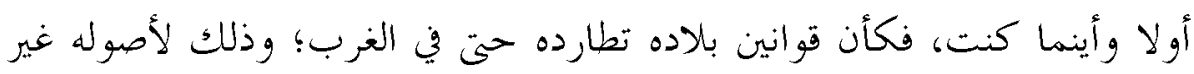
الأوربية الواضحة من مظهره أو من شكله.

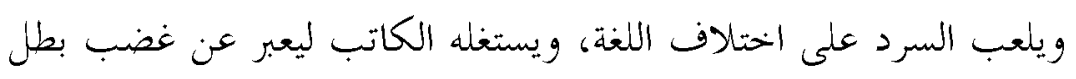

رواية وأطوف عاريا، فيجعله يسب الآخر من أهل المهجر وينغس عن غضبه المختقن ومشاعر الاضطهاد والظلم الذي يتعرض له، والتلاعب بأعصابه، كما في هذا لها

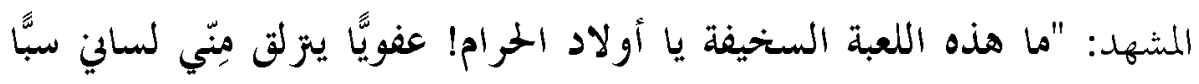

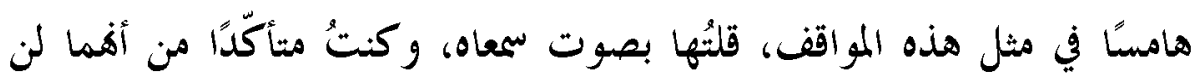

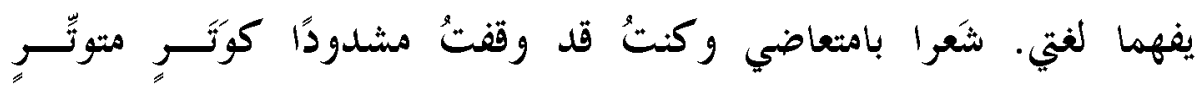

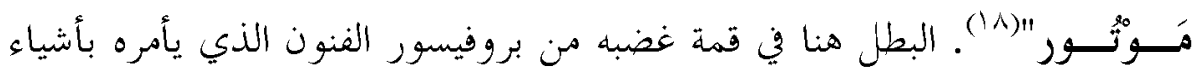
غريبة ويهتم ببكس البطل ولا يهتم بلوحاته التي يعرضها عليهم في المعهد. هو يعرض عليهم فنه ولوحاته وهم لا يرون فيه غير جسده الصالح للعرض على الطلبة

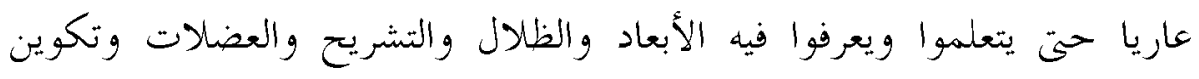

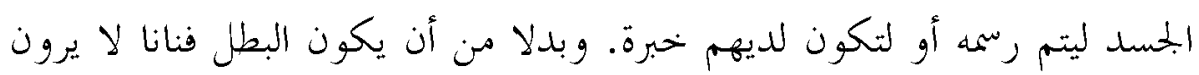
فيه أكثر من عارض يعرض جسده عاريا عليهم. الإنسان الأوربي بثقافته ومعارفه وذهنيته في مقابل شخصية بطل معل الرواية العربي، وهو ما يكرس لفكرة المقابلة أو التناقض بين النماذج البشرية، ويصنع 
المفارقة، ويمعل شخصيات الرواية في حال من التراع أو التعارض في الوظائف

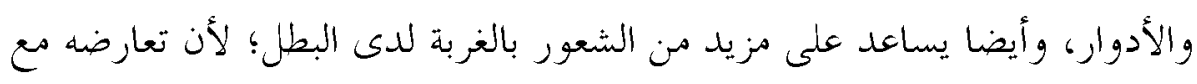

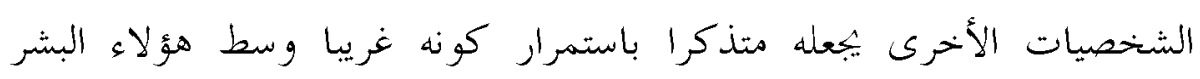
المختلفين عنه، فهم لهم سلوكيات وتصرفات وعادات وتقاليد مختلفة دائما عنه،

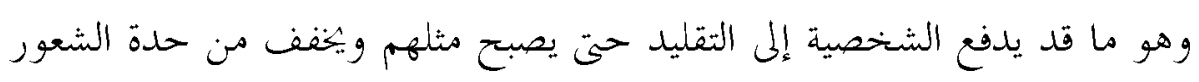

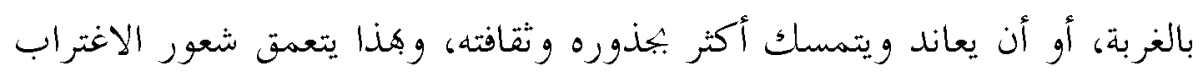
والفقد، ويظل متذكرا للماضي ولحياته القديمة قبل الهجرة.

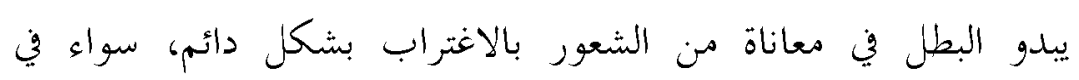

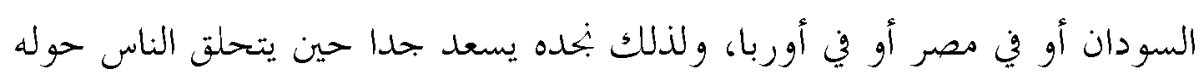
أو يجد أصدقاء كثيرين، وينعكس هذا عليه داخليا، ويظهر في سلوكياته أو أو تصرفاته؛ مثلما وجد في صحبة سارة وآدم والعائلة السودانية التي تعيش في عين شمس بالقاهرة، كما يتضح من هذا المقطع: "جلسنا نأكل جميعًا. وهي لحظات

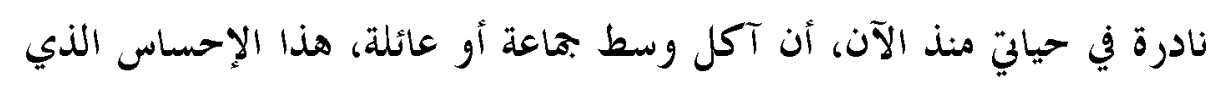
يجعلني أشعر فورا بشهية أكبر من العادة. بعدها جاء الثاي وبدأت المسامرات الطويلة الحميمة"(9"). فيظهر لديه اشتياق لروح الأسرة وتحلق الناس حوله. ويتحدد الموقف النفسي للسارد من بعض الشخصيات من خلال التصريح

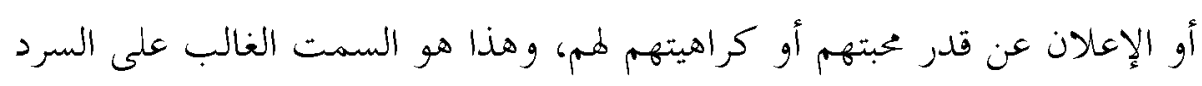
في أغلب روايات طارق الطيب؛ حيث البطل هو المتكلم وهو السارد الذي يعلن مواقفه من كافة الشخصيات ويمدد مشاعره بتاههم؛ كما يظهر مع شخصية

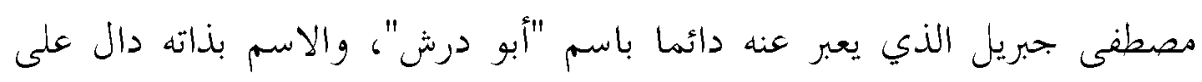
التحبب وأن الشخصية مقربة منه. كما يظهر هذا الإعلان في الموقف التالي:

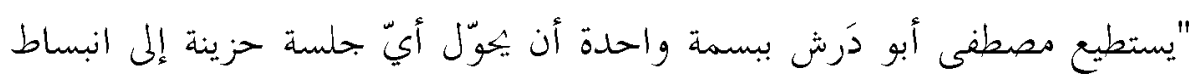

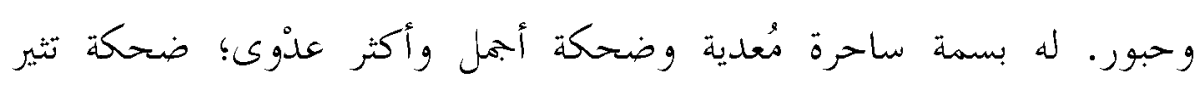


الضحك والفضول لدى الآخرين. ما إن يبتسم حتى تتحوّل صرامة وجهه إلى

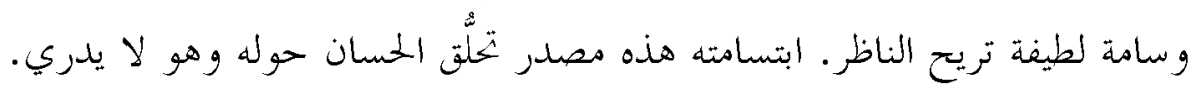

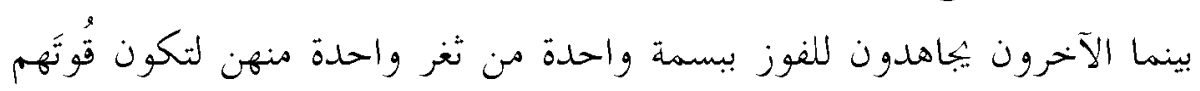
العاطفي الناعم ليوم بالغ الخشونة"(·"ج).

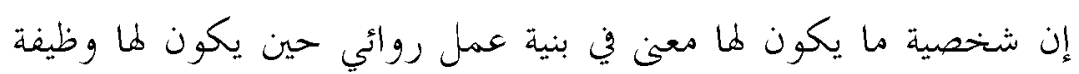

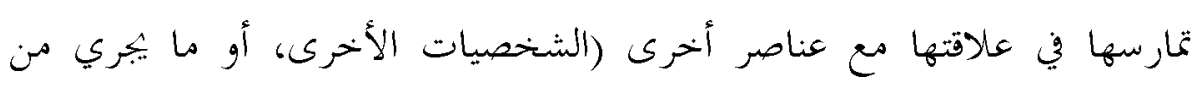

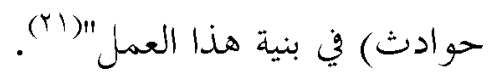




\section{|لإمادروالمراجع}

الطيب، طارق، اذكروا محاسن، (بحموعة قصصــية)، الطبعــة الأولى، دار

$$
\text { شرقيات-القاهرة، (991 إم). }
$$

الأسانسير. مسرحية. السلام للطباعة والنشر-القاهرة، (ب9.99 (19)..

بيت النخيل. الطبعة الثالثة، دار الحضارة للنشر-القاهرة،(؟ . . ب) . الجمل لا يقف خلف إثلارة حمــــاء. (بخموعـــة قصصــية)، القــاهرة،

$$
\cdot(\text { ( } 1994)
$$

حقيبة محلوءة بحمام وهديل. (بحموعة شعرية). دار سيلينه للنشر - فيينـا،

$$
\cdot(\text { (1999) }
$$

محطات من السيرة الذاتية. دار العين للنشر-الإسكندرية، (Y . . Y). حجر أكبر من السماء ـ (مجموعة شــعرية). دار ســكوبيه - مقـــدونيا،

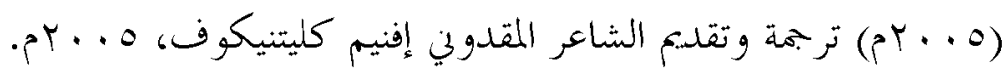
مدن بلا نخيل. الطبعة الأولى، دار الحضارة للنشر-القاهرة، (7 . . بم).

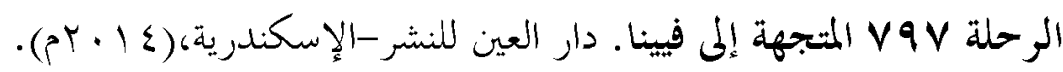

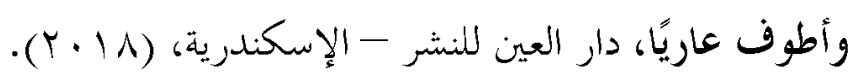

$$
\text { المراجع: }
$$

أحمد، محمد فتوح، الرمز والرمزية في الثعر المعاصر، الطبعة الثالثــة. دار

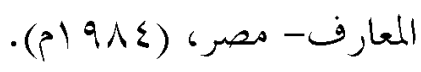

إيكو، إمبرتو. التأويل والتأويل المفرط. ترجهة: ناصر الحلواني. هيئة قصــر

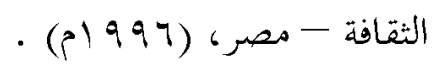

برو كميير، جينز، و كربو، دونال ، السرد والهوية، ترجمة عبد المقصود عبد

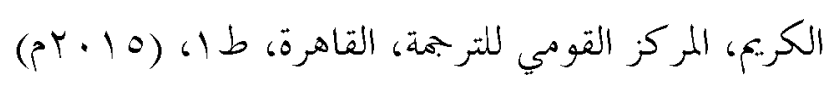


بوعزة، محمد، تحليل النص السردي، الدار العربية للعلوم ناشرون، بيروت،

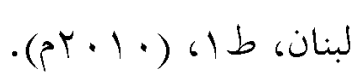

تاديبه، جان إيف. النقد الأدبي في القرن العشرين. ترجمة د. مندر عيــاش.

$$
\text { مركز الإنماء الحضاري-حلب-سوريا، (1994 ام). }
$$

تودوروف، تزفيتان، الثعرية، ت. شكري المبخوت ورجاء بن سلامة، دار

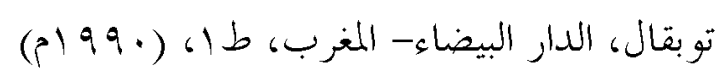

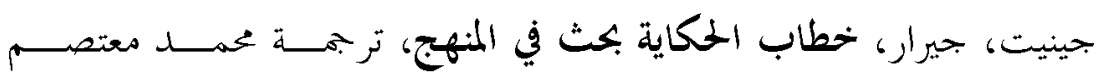

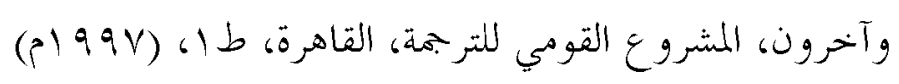

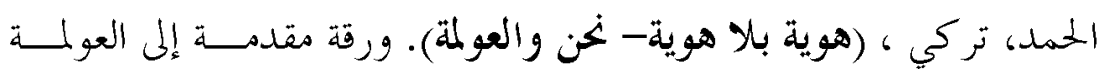

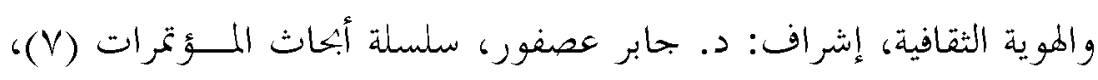

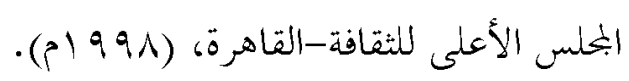

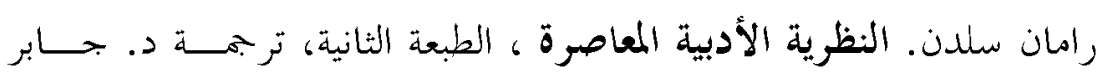
عصفور س إقامة الترجمة ـ ا ، هيئة قصور الثقافة- مصر، (997 (م). رشوان، ناجي. الوعي الحضاري وأساطير التصور. سلسلة كتابات نقدية-

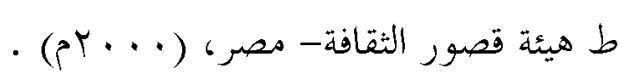

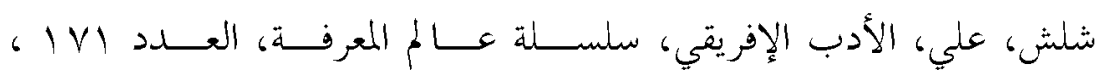
$\cdot($ ( 1994$)$

شوشة، محمد سليم، فاعلية المهجر في الحطاب الروائي، بجلة كليــة الآداب

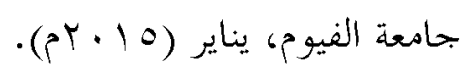
شوشة، محمد سليم، خريف الغربة وجماليات الألم، مقالة، جريســـة أخبــار

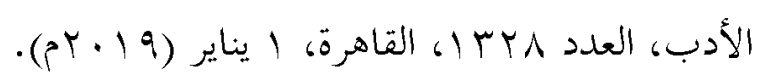
طبانة، بدوي أحمد ، نظرات في أصول الأدب والنقــد، الطبعــة الأولى.

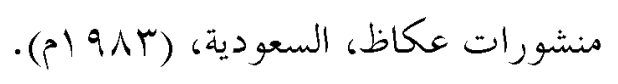


عطية، هدى. جماليات المكان في الثعر المعاصر بين كتابات نقدية. الطبعة

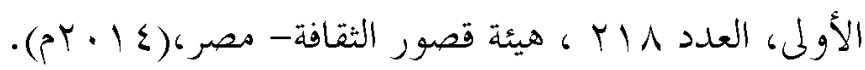
العيد، يمنى ، تقنيات السرد الروائي في ضوء المنهج البنيوي، دار الفارابي،

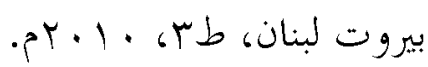
تامر، فاضل، اللغة الثانية (في إشكالية المنهج والنظرية والمصطلح). الطبعة

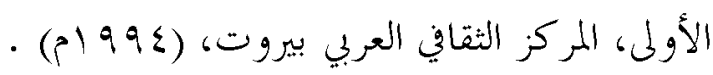

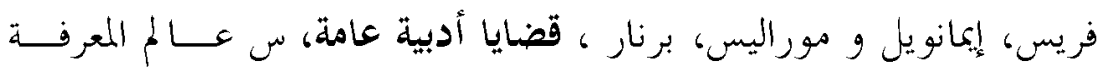

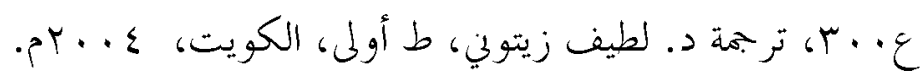
فولفجانج إيسر، فعل القراءة-نظرية في الاستجابة الجماليــة. ترجمــة د.

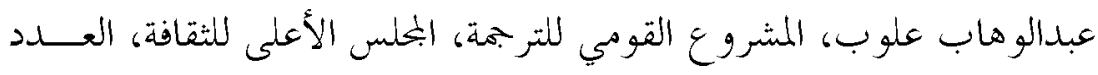

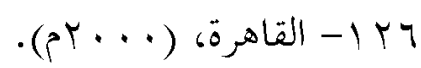

فيليب هامون، سيميولوجية الشخصيات الروائية، ترجمة سعيد بنكراد، دار

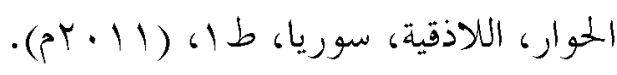

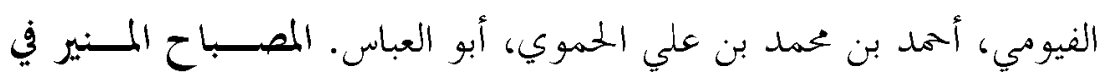

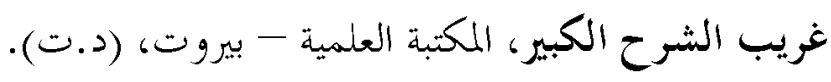

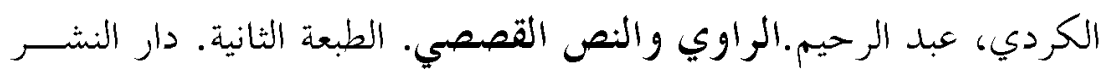
للجامعات - القاهرة، (1997 ام). الكفوي، أيوب بن موسى الحسيني، أبو البقاء الحنفي. الكليات معجــم في المصطلحات والفروق اللغوية. الطبعة الثانية. تحقيق: عدنان درويش ومحمد

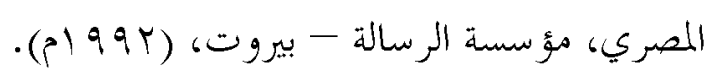

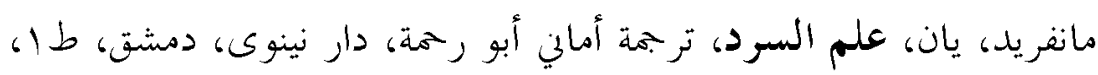

$$
\text { pr. } 11
$$


بحموعة مؤلفين، طرائق تحليل السرد الأدبي دراســات، الطبعــة الأولى.

$$
\text { منشورات اتحاد كتاب المغرب-الرباط، (1994 اجم). }
$$

مرتاض، عبد الملك، في نظرية الرواية، عالم المعرفة، الكويـــ، ديســمبر

$$
\cdot(\text { ( } 1991)
$$

المعتوق، أحمد محمد، الحصيلة اللغوية، سلسلة عالم المعرفة-الكويت، العدد

$$
\text { . }
$$

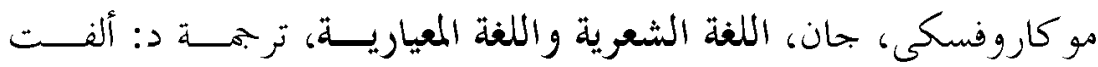

$$
\text { الروبي. بجلة فصول، العددد ا، الخخلد الخامس، القاهرة (ع هو 1) ). }
$$

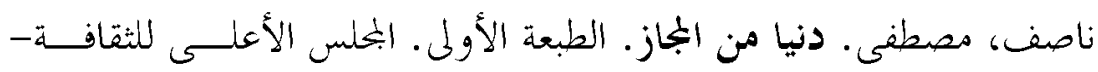

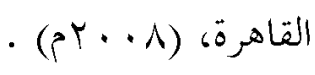

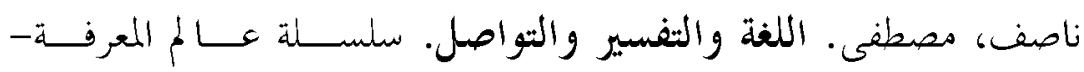

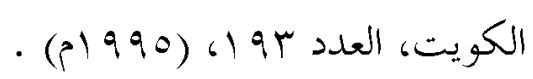

النصير، ياسين، الرواية والمكان، دار الثؤون الثقافية العامة، وزارة الثقافة،

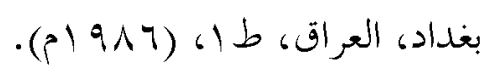




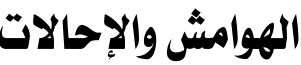

(1) فيليب هامون، سيميولوجية الشخصيات الروائية، ترجمة سعيد بنكـــاد، دار الخـــوار،

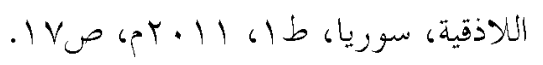

(T) يمن العيد، تقنيات السرد الروائي في ضوء المنهج البنيوي، صVاء.

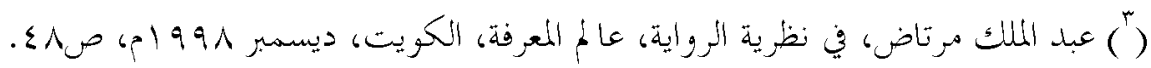

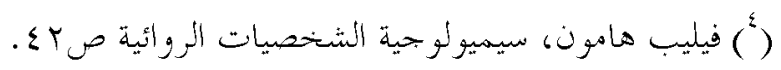$$
\text { (0) فيليب هامون، السابق، صر ب وال بعله. }
$$

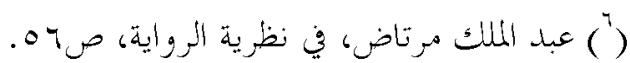

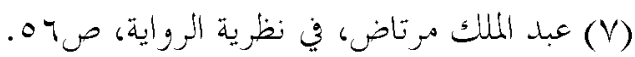

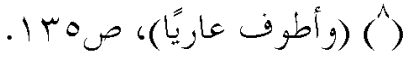

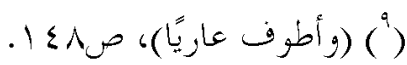

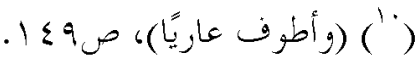

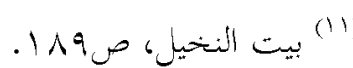

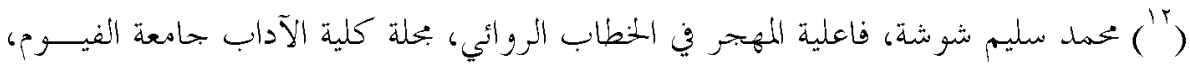

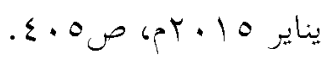

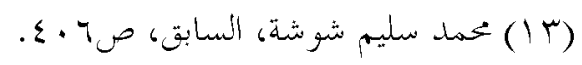

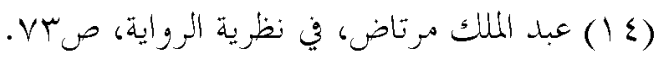

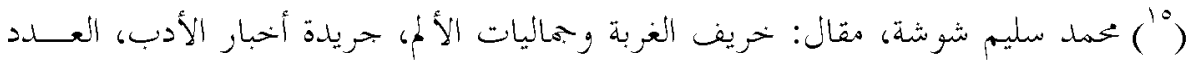

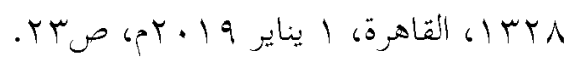

$$
\begin{aligned}
& \text { (T (1) بيت النخيل، ص r بr وما بعدها. }
\end{aligned}
$$

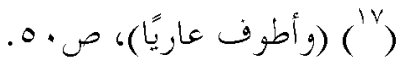

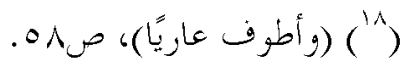

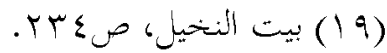

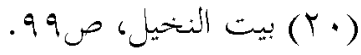

$$
\begin{aligned}
& \text { (Y) (Yمن العيد، تقنيات السرد الروائي في ضوء المنهج البنيوي، صبه }
\end{aligned}
$$

